\title{
PENGARUH COOPERATIVELEARNINGTIPE STUDENT \\ TEAMSACHIEVEMENT DIVISION(STAD)TERHADAP HASIL BELAJAR IPS TERPADU SISWAKELAS VIII SEMESTER GENAP SMP MUHAMMADIYAH 1 METRO T.P 2015/2016.
}

\author{
Wakijo \\ Program Studi Pendidikan Ekonomi FKIP Universitas Muhammadiyah Metro \\ Wakijo12umm@Gmail.Com
}

\begin{abstract}
Abstrak
Tujuan dalam penelitian ini adalah untuk mengetahui pengaruh penggunaan Cooperative Learning tipe STAD terhadap hasil belajar IPS Terpadu siswa kelas VIII semester Genap SMP Muhammadiyah 1 Metro Tahun Pelajaran 2015/2016. Berdasarkan penelitian ini metode eksperimen mengguanakan bentuk quasi experiemental design nonequivalent control group design. Dalam penelitian ini populasinya adalah seluruh peserta didik kelas VIIID SMP Muhammadiyah 1 Metro yang sebanyak 5 kelas dengan jumlah 123 peserta didik. Sampel adalah bagian dari jumlah dan karakteristik yang dimiliki oleh populasi tersebut. Sehingga diperoleh bahwa kelas VIII $I_{D}$ ang berjumlah 24sebagai kelas eksperimen dan kelas VIII $_{\mathrm{E}}$ yang berjumlah 27 sebagai kelas kontrol. Berdasarkan perhitungan dengan rumus regresi linier sederhana dengan menggunakan $t_{\text {hitung }}\left(t_{o}\right)$ dalam analisis data dapat diketahui bahwa analisis perhitungan nilai tersebut $t_{\text {hitung }}>t_{\text {tabel }}$. Pada taraf signifikan 5\% yaitu $9,10>1,72$ dan pada taraf signifikan $1 \%$ yaitu $9,10>2,51$. Jika $t_{\text {tabel }}$ dengan $t_{\text {hitung }}>t_{\text {tabel }}$ berarti hipotesisnya diterima. Dan apabila $t_{\text {hitung }}<t_{\text {tabel }}$ berarti hipotesisnya ditolak. Dengan demikian, pengaruh penggunaan model Cooperative Learning tipe Student Teams Achivement Division terhadap hasil belajar IPS Terpadu peserta didik Kelas VIII Dsemester genap SMP Muhammadiyah 1 Metro tahun pelajaran 2015/2016 hipotesisnya dapat diterima/ dibuktikan.
\end{abstract}

Kata kunci: Cooperative LearningTipeStudent Teams Achievement Division(STAD), Dan Hasil Belajar

\section{PENDAHULUAN}

Belajar adalah proses perubahan perilaku sebagai akibat dari interaksi individu dan lingkungan (semua faktor yang di luar individu). Kemampuan manusia untuk belajar adalah ciri penting yang membedakan jenis manusia dari jenis makhluk lain. Dengan kemampuan belajar dapat memberikan manfaat bagi individu dan juga masyarakat. Bagi individu, dengan kemampuannya untuk belajar secara terus menerus memberikan sumbangan bagi pengembangan berbagai 
gaya hidup. Kegiatan membaca, menulis, main gitar merupakan sedikit contoh kegiatan belajar. Bagi masyarakat, belajar memainkan peranan penting dalam meneruskan kebudayaan berupa kumpulan pengetahuan untuk diberikan kepada generasi berikutnya. Melalui belajar, dimungkinkan memperoleh temuantemuan berdasarkan perkembangan dari waktu ke waktu.

Hasil belajar adalah perubahan, yang di mana seseorang dikatakan sudah belajar apabila perilakunya menunjukan perubahan, dari awalnya tidak tahu menjadi tahu, dari tidak bisa menjadi bisa. Produk belajar berupa perubahan perubahan perilaku, proses mental di mana hasil belajar harus selalu di terjemahkan ke dalam perilaku atau tindakan yang dapat diamati.

Dari hasil prasurvey bahwa dalam pembelajaran guru menggunakan metode ceramah bervariasi. Dengan metode tersebut siswa kurang efektif dalam proses pembelajaran, karena masih banyak ditemukan siswa yang kurang memperhatikan, bosan, dan kurang bisa berfikir tentang materi pembelajaran. Karena dalam proses pembelajaran siswa tidak mengembangkan pengetahuannya.

\section{KAJIAN PUSTAKA}

\section{PembelajaranCooperative Learning Tipe STAD}

Menurut Slavin (Isjoni, 2009:51) pembelajaran tipe STAD ini merupakan salah satu tipe cooperative yang menekankan pada adanya aktivitas dan interaksi di antara siswa untik saling memotivasi dan saling membantu dalam menguasai materi pelajaran guna mencapai prestasi yang maksimal.

Menurut Ratumanan (2002:13), bahwa pembelajaran cooperative tipe STAD dikembangkan oleh Robert Slavin dan teman-temannya di Universitas John Hopkin, merupakan salah satu tipe pembelajaran yang paling sederhana, sehingga tipe ini dapat dimanfaatkan oleh guru-guru yang baru menggunakan pendekatan pembelajaran cooperative.

Berdasarkan definisi di atas dapat diambil kesimpulan bahwa pembelajaran Cooperative tipe Student TeamsAchievement Division adalah strategi dalam pembelajaran yang menekankan pada aktivitas siswa untuk menguasai materi pada pembelajaran ini siswa dikelompokkan dalam kelompokkelompok kecil yang kemudian siswa saling berinteraksi dan saling membantu 
siswa lainnya dalam menyelesaikan tugas yang diberikan guru.

Menurut Slavin (2008:143) ada 5 indikator dalam pembelajaran kooperatif tipe student teams-achievement division, yaitu:

a) Presentasi kelas

Guru

memulaidenganmenyampaikanindikat or yang harusdicapaidilanjutkandenganmembe rikanpersepsidengantujuanmengingatk ansiswaterhadapmateriprasyarat yang akandipelajari agar siswadapatmenghubungkanmateri yang akandipresentasikan.

b) Tim/Tahap Kerja kelompok

Padatahapiniterdiridari

siswadiberilembartugas yang akandipelajari. Dalamkerjakelompok, siswasalingberbagitugas. Guru sebagaifasilitatordan motivator.

c) Kuis/Tahap Tes Individu

Diadakanpadaakhirpertemuankeduada nketiga, kira-kira 10 menituntukmengetahui yang telahdipelajarisecaraindividu, selamamerekabekerjadalamkelompok dansiswatidakbolehsalingmembantuda lammengerjakantugas.

d) TahapPenghitunganSkor
Yang

dihitungberdasarkanskorawal.Tahapin idilakıkan a oar

e) TahapPemberianPenghargaan Tim akanmendapatkanpenghargaansertifik atataubentukpenghargaan lain apabilaskor rata-rata merekamencapaikriteriatertentu.

Kelebihan Dan Kekurangan Menurut Slavin (Kurniasih dkk 2015:22)

a) Kelebihan STAD

1) Karena adanya kelompok siswa yang dituntut aktif sehingga medel ini siswa dengan sendirinya akan percaya diri dan meningkat kecakapan individunya.

2) Interaksi sosial yang terbangun dalam kelompok, dengan sendirinya siswa belajar dalam bersosialisasi dengan lingkungannya (kelompok).

3) Dengan kelompok yang ada, siswa diajarkan untuk membangun komitmen dalam mengembangkan kelompoknya.

4) Mengajarkan menghargai orang lain dan saling percaya.

5) Dalam kelompok siswa diajarkan untuk saling mengerti dengan materi yang ada, sehingga siswa 
saling memberitahu dan mengurangi sifat kompetitif

b) Kelemahan STAD

1) Karena tidak adanya kompetisi diantara anggota masing-masing kelompok, anak yang berprestasi bisa saja menurun semangatnya.

2) Jika guru tidak bisa mengarahkan anak, maka anak yang berprestasi bisa jadi lebih dominan dan tidak terkendali.

\section{HasilBelajar}

Menurut Bell-Gredler (Karwono (dkk), 2012:13) "belajar adalah proses yang dilakukan oleh manusia untuk mendapatkan aneka ragam kemampuan, keterampilan, dan sikap yang diperoleh secara bertahap dan berkelanjutan".Selanjutnya Yusuf (2015:181) menyebutkan "hasil belajar merupakan wujud pencapaian peserta didik sekaligus merupakan lambang keberhasilan pendidik dalam membelajarkan peserta didik".Sedangkan Suprijono (2015:7) mengemukakan bahwa "hasil belajar adalah perubahan perilaku secara keseluruhan bukan hanya salah satu aspek potensi kemanusiaan saja”.

Berdasarkan pendapat tersebut maka dapat dikatakan bahwa hasil belajar adalah perubahan perilaku atau hasil yang

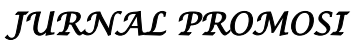
Jurnal Pendidikan Ekonomi UM MMetro diperoleh siswa setelah menerima suatu pengetahuan yang diwujudkan dalam bentuk skor atau angka setelah mengikuti tes.

Faktor-faktor yang mempengaruhi hasil belajar Menurut Slameto (2003: 54-72), yaitu:

\section{1) Faktor internal} yaitu faktor yang ada dalam diri individu yang sedang belajar, faktor intern terdiri dari:

a) Faktor jasmaniah (kesehatan dan cacat tubuh)

b) Faktor psikologis (inteligensi, perhatian, minat, bakat, motif, kematangan dan kesiapan)

c) Faktor kelelahan

2) Faktor eksternal yaitu faktor dari luar individu. Faktor ekstern terdiri dari:

a) Faktor keluarga (cara orang tua mendidik, relasi antara anggota keluarga, suasana rumah, keadaan ekonomi keluarga, pengertian orang tua, dan latar belakang kebudayaan)

b) Faktor sekolah (metode mengajar guru, kurikulum, relasi guru dengan siswa, relasi siswa dengan siswa, disiplin sekolah, alat 
pelajaran, waktu sekolah, standar belajar diatas ukuran, keadaan gedung, metode belajar dan tugas rumah

c) Faktor masyarakat (kegiatan siswa dalam masyarakat, mass media, teman bergaul, dan bentuk kehidupan masyarakat).

\section{METODE PENELITIAN}

Penelitian ini merupakan penelitian yang bersifat pengaruh, yang mengkaji pengaruh variabel bebas terhadap variabel terikat. Penelitian ini mencari bagaimana pengaruh penggunaan pembelajaran Cooperative Learning tipe Student Theams-Achievement Division terhadap hasil belajar ekonomi dengan mengguanakan metode ekperimen (treatment) sebagai metode dalam pengumpulan data hasil belajar. Dari data yang terkumpul kemudian dianalisis untuk menguji hipotesis yang telah dirumuskan sebelumnya. Dan dari hasil pengujian hipotesis yang telah di analisis maka nantinya akan didapat dijadikan sebagai landasan untuk mengambil kesimpulan.

Dalam hal ini yang menjadi populasi penelitian adalah seluruh siswa kelas VIII SMP Muhammadiyah 1 Metro tahun pelajaran 2015/2016, yang terdiri dari $\mathrm{V}$ kelas dengan jumlah 24 siswa dari setiap kelas, sehingga total populasi siswa dari seluruh kelas sebanyak 125 siswa. Dapat dilihat pada tabel sebagai berikut :

Tabel 2. Populasi siswa

\begin{tabular}{|c|c|c|}
\hline No & Kelas & Jumlah \\
\hline 1. & VIIIA & 24 \\
\hline 2. & VIIIB & 24 \\
\hline 3. & VIIIC & 24 \\
\hline 4. & VIIID & 23 \\
\hline 5. & VIIIE & 30 \\
\hline \multicolumn{2}{|c|}{ Total } & 125 \\
\hline
\end{tabular}

Sampel merupakan sejumlah individu yang ditunjuk mewakili populasi dalam suatu penelitian. Dalam penelitian ini, peneliti menggunakan teknik sampeling porposive yaitu menentukan sampel dengan pertimbangan tertentu, pemilihan kelas yang menurut peneliti sesuai dan yang pas untuk menjadi sampel untuk mewakili populasi dengan jalan observasi terlebih dahulu. Dari kutipan tersebut, dapat dijadikan sebagai pedoman dalam pengambilan sampel yaitu dengan menuliskan kelas dan jumlah siswa untuk kemudian diobservasi dan dijadikan sebagai sampel penelitian. Sehingga diperoleh bahwa kelas VIII D yang berjumlah 24 siswa sebagai sampel dan kelas VIII E yang berjumlah 24 siswa sebagai kelas kontrol dalam penelitian.

PEMBAHASAN HASIL PENELITIAN 
Berdasarkan penelitian yang dilakukan oleh penulis dapat disimpulkan bahwa hasil pengumpulan data dalam penelitian dari 24 peserta didik yang sebelum diberikan perlakuan (treatment) penggunakan model pembelajaran kooperatif tipe Student Teams Achivement Division, peserta didik yang hasil belajar IPS Terpadu termasuk dalam kategori tuntas sebanyak 5 peserta didik, sedangkan peserta didik yang hasil belajar IPS Terpadu termasuk dalam kategori belum tuntas sebanyak 19 peserta didik. Setelah 24 peserta didik yang diberikan perlakuan (treatment) penggunakan model pembelajaran kooperatif tipe Student Teams Achivement Division, peserta didik yang hasil belajar IPS Terpadu termasuk dalam kategori tuntas sebanyak 14 peserta didik, sedangkan peserta didik yang hasil belajar IPS Terpadu termasuk dalam kategori belum tuntas sebanyak 10 peserta didik

Pada pengujian dengan menggunakan rumus Regresi Linier Sederhana diperoleh $\mathrm{a}=22,8804, \mathrm{~b}=0,7732$, sehingga dengan demikian $\hat{Y}=a+b X$, adalah $\hat{\mathrm{Y}}=$ 22,8804+ 0,7732X. Kemudian, dari hasil analisis yang dilakukan maka terbukti bahwa ada pengaruh yang positif penggunaan model pembelajaran kooperatif tipe Student Teams Achivement Division terhadap hasil belajar IPS JURNAL PROMOSI Jurnal Pendidikan Ekonomi UM MMetro
Terpadu pada peserta didik kelas VIII D SMP Muhammadiyah 1 Metro. Hal ini dibuktikan dengan penghitungan analisis data dapat diketahui bahwa nilai tersebut $t_{\text {hitung }}>\mathrm{t}_{\text {tabel }}$, dan terlihat bahwa pada taraf signifikan $5 \%$ yaitu 9,10>1,72. Dan pada taraf signifikan $1 \%$ yaitu $9,10>2,51$, yang dapat dilihat pada daftar $G$ tabel statistik. Dengan demikian maka hipotesis diterima.

Berdasarkan kesimpulan yang penulis uraikan di atas, dan untuk perbaikan proses pembelajaran IPS Terpadu itu sendiri, maka sesuai dengan hasil penelitian yang telah penulis laksanakan maka penulis akan menyampaikan saran-saran sebagai berikut:

a) Untuk meningkatkan hasil belajar diharapkan guru menjadi fasilitator dan motivator, sehingga peserta didik menjadi lebih aktif dalam proses pembelajaran dan penerapan model cooperative learning tipe Student Teams Achivement Division diharapkan bisa diterapkan sehingga peserta didik dapat lebih semangat dalam belajar dan tentunya dapat melatih agar peserta didik dapat bekerja sama dengan baik.

b) Peserta didik dapat lebih aktif dalam proses pembelajaran terutama dalam penerapan model kooperatif 
khususnya tipe Student Teams

Achivement Division.

c) Harapannya dengan cara seperti ini, dapat meningkatkan Hasil Belajar Peserta didik. Dengan begitu proses pembelajaran lebih inovatif dan selalu mengalami pembaharuan.

d) Untuk meningkatkan hasil belajar diharapkan Sekolah dapat memberikan fasilitas atau sarana dan prasarana yang memadai agar pendidik maupun peserta didik dapat lebih bersemangat dan nyaman ketika proses pembelajaran berlangsung.

Dengan tiga hal tersebut di atas mudah-mudahan dapat bermanfaat dengan baik untuk meningkatkan hasil belajar peserta didik dalam proses pembelajaran.

\section{KESIMPULAN}

Berdasarkan penelitian yang dilakukan oleh penulis dapat disimpulkan bahwa hasil pengumpulan data dalam penelitian dari 24 peserta didik yang sebelum diberikan perlakuan (treatment) penggunakan model pembelajaran kooperatif tipe Student Teams Achivement Division, peserta didik yang hasil belajar IPS Terpadu termasuk dalam kategori tuntas sebanyak 5 peserta didik, sedangkan peserta didik yang hasil belajar IPS Terpadu termasuk dalam kategori belum tuntas sebanyak 19 peserta didik. Setelah
24 peserta didik yang diberikan perlakuan (treatment) penggunakan model pembelajaran kooperatif tipe Student Teams Achivement Division, peserta didik yang hasil belajar IPS Terpadu termasuk dalam kategori tuntas sebanyak 14 peserta didik, sedangkan peserta didik yang hasil belajar IPS Terpadu termasuk dalam kategori belum tuntas sebanyak 10 peserta didik. Pada pengujian dengan menggunakan rumus Regresi Linier Sederhana diperoleh $\mathrm{a}=22,8804, \mathrm{~b}=$ 0,7732, sehingga dengan demikian $\hat{Y}=a+$ $b X$, adalah $\hat{\mathrm{Y}}=22,8804+0,7732 \mathrm{X}$. Kemudian, dari hasil analisis yang dilakukan maka terbukti bahwa ada pengaruh yang positif penggunaan model pembelajaran kooperatif tipe Student Teams Achivement Division terhadap hasil belajar IPS Terpadu pada peserta didik kelas VIII D SMP Muhammadiyah 1 Metro. Hal ini dibuktikan dengan penghitungan analisis data dapat diketahui bahwa nilai tersebut $t_{\text {hitung }}>t_{\text {tabel }}$, dan terlihat bahwa pada taraf signifikan 5\% yaitu $9,10>1,72$. Dan pada taraf signifikan $1 \%$ yaitu $9,10>2,51$, yang dapat dilihat pada daftar $G$ tabel statistik. Dengan demikian maka hipotesis diterima.

Berdasarkan kesimpulan yang penulis uraikan di atas, dan untuk perbaikan proses pembelajaran IPS Terpadu itu sendiri, maka sesuai dengan hasil penelitian yang 
telah penulis laksanakan maka penulis akan menyampaikan saran-saran sebagai berikut:

1) Untuk meningkatkan hasil belajar diharapkan guru menjadi fasilitator dan motivator, sehingga peserta didik menjadi lebih aktif dalam proses pembelajaran dan penerapan model cooperative learning tipe Student Teams Achivement Division diharapkan bisa diterapkan sehingga peserta didik dapat lebih semangat dalam belajar dan tentunya dapat melatih agar peserta didik dapat bekerja sama dengan baik.

2) Peserta didik dapat lebih aktif dalam proses pembelajaran terutama dalam penerapan model kooperatif khususnya tipe Student Teams Achivement Division.

3) Harapannya dengan cara seperti ini, dapat meningkatkan Hasil Belajar Peserta didik. Dengan begitu proses pembelajaran lebih inovatif dan selalu mengalami pembaharuan.

4) Untuk meningkatkan hasil belajar diharapkan Sekolah dapat memberikan fasilitas atau sarana dan prasarana yang memadai agar pendidik maupun peserta didik dapat lebih bersemangat dan nyaman ketika proses pembelajaran berlangsung.
Dengan tiga hal tersebut di atas mudah-mudahan dapat bermanfaat dengan baik untuk meningkatkan hasil belajar peserta didik dalam proses pembelajaran.

\section{JURNAL PROMOSI} Jurnal Pendidikan Ekonomi UM Metro

Altabeta, slameto. 2UU3. Belajar dan Faktor-Faktor yang Mempengaruhinya. Jakarta. PT. Rineka Cipta.

Isjoni, 2009. Cooperative Learning. Bandung : Alfabeta

Karwono (dkk), 2012. Belajar dan Pembelajaran. Bandung : Rajagrafindo Persada

Kurniasih, Imas Berlin Sani, 2015. Model Pembelajaran. Kata Pena.

Ratumanan, T. G. 2002. Belajar dan Pembelajaran. Surabaya. Unesa University Press

Rober E Slavin. 2008. Cooperative Learning Teori, Riset Dan Praktek. Bandung: Nusa Media

Suprijono, Agus 2015. Cooperative Learning. Yogyakarta : Pustaka Pelajar.

Universitas Muhammadiyah Metro. 2015. Pedoman Penulisan Karya Ilmiah Metro: $\quad$ FKIP Universitas Muhammadiyah Metro.

Yusuf, Muri 2015. Asesmen dan Evaluas 
ISSN: 2442-4994 Vol.4. NNo.1 (2016) 1-8 